\title{
Interest and deferred consumption in the rat
}

\author{
JAMES ALLISON and MATTHEW C. WOOD \\ Indiana University, Bloomington, Indiana
}

\begin{abstract}
Under a baseline condition, thirsty rats put water on account by licking an empty spout for a fixed number of licks at a water spout. Under interest-bearing conditions, they could enlarge this account by waiting longer than they did in baseline to make the first lick at the water spout (lick latency), or the next lick in a series of water licks (interlick interval). The account grew at two different interest rates, $15 \%$ and $25 \%$ of the remainder. The rats deferred consumption by increasing the interlick interval in response to the $15 \%$ interest rate, but not the $25 \%$ rate. Interest had no effect on latency. We interpret the results in terms of (1) the concept of target saving, and (2) a substitution effect that discourages, and an income effect that encourages, present consumption. The results have implications for the study of self-control.
\end{abstract}

Economists disagree about interest and the deferment of consumption. Keynesians hold that interest has a negligible effect on savings (Boskin, 1978; Keynes, 1936; Weber, 1970), and contemporary macromodels typically omit an interest rate variable. Empirical studies conflict: Weber (1970) concluded that higher interest rates went with more consumption and less saving, but others drew the opposite conclusion (Boskin, 1978; Wright, 1969).

Those conclusions rest precariously on correlational analyses of income, tax, and investment statistics (Hall \& Taylor, 1988). As a small step toward experimental certainty, we report an attack on this problem with rats in the role of consumers.

We fashioned our procedure as an interest-bearing savings account, with special attention to one paramount feature. If we bank $\$ 10,000$ to accrue interest, we can make a small withdrawal without jeopardizing significant interest earnings. In like manner our thirsty rat, having earned the chance to make a certain number of licks at a water spout, could lick right away but still enlarge the remainder by licking more slowly thereafter.

We tested naive Sprague-Dawley males in a chamber monitored by a microcomputer (Buxton \& Allison, 1990). Motorized shutters controlled access to an empty metal spout and, $6.4 \mathrm{~cm}$ to its right, a metal water spout. An electronic circuit detected licks. Each session lasted $60 \mathrm{~min}$.

The rats always had laboratory chow, but never drank outside the daily test session. Under the baseline schedule, when the rat had completed 20 licks at the empty spout, the left shutter moved down and the right moved up simultaneously, exposing the water spout. When the rat had completed 20 water licks, the right shutter moved

We thank Bill Timberlake and Arlie Williams for their comments, Alison Buxton for help in improving the manuscript, Jim Logan for programming, and Joe Steinmetz for sharing his machines. Address correspondence to James Allison, Department of Psychology, Indiana University, Bloomington, IN 47405. down and the left moved up, exposing the empty spout. Test Phases 1, 3, and 5 provided measurements of latency and interlick interval under this baseline condition with $0 \%$ interest, where the rats could earn water only by licking the empty spout. We used interest rates of $15 \%$ in Phase 2, and $25 \%$ in Phase 4 . The repeated testing at $0 \%$ provided an estimate of order effects.

Each rat moved to the next phase after five consecutive sessions that appeared stable on five measures: median interlick interval (the time between successive water licks); median latency (the time between the raising of the water-spout shutter and the first water lick); the total number of water licks; total water consumption; and efficiency, the number of water licks $/ \mathrm{ml}$. The 6 rats that met these rigorous stability criteria averaged seven sessions per phase. Three others fell short in one phase or another during the time limit of the experiment, and we used none of their data.

Among the last five sessions of each phase, each session provided a median interlick interval for the individual rat. We defined the criterion session as the one that contained the median of the five median interlick intervals. Each rat yielded five criterion sessions, one per phase.

In computing interest earned for deferment of consumption in Phases 2 and 4, we used separate compounding periods for latency and interlick interval. Thus, the rat could accrue licks by delaying its first water lick for a certain time (its latency compounding period), or any successive water lick for another time (its interlick interval compounding period). To select the two compounding periods, we examined the latencies and interlick intervals from the first baseline criterion session, and we chose the times that separated the top $15 \%$ from the rest. These times were typically based on approximately 3,000 water licks. For example, if about $15 \%$ of a rat's latencies were above $1,000 \mathrm{msec}$, and $85 \%$ below, its latency compounding period would be $1,000 \mathrm{msec}$. Once the water spout appeared, the rat would have to wait at least $1,000 \mathrm{msec}$ to earn interest on the latency of its first lick. Similarly, if its interlick interval compounding period were 
$195 \mathrm{msec}$, the rat would have to wait at least $195 \mathrm{msec}$ between two successive licks to earn interest on an interlick interval.

The principal on which we computed interest was the number of water licks left in the account. For example, at the moment of access, the program would place 20 water licks on account. Suppose the compounding periods were $1,000 \mathrm{msec}$ for latency, and $195 \mathrm{msec}$ for interlick interval. On a latency of only $950 \mathrm{msec}$, the account would fall to 19. But if the next lick came $400 \mathrm{msec}$ later, this 400 -msec interlick interval would earn $15 \%$ of 19 , or 2.85 licks, and the account would go to $20.85: 20 \mathrm{mi}-$ nus the first 2 , leaving 18 plus 2.85 earned from the first interlick interval. Cumulative wealth, defined as licks already spent plus those still on account, would then be 22.85 water licks: the initial 20 , plus 2.85 gained for deferring the second lick. This process would continue until the account ran dry, whereupon the water shutter would fall, and 20 more empty licks would replenish the depleted water-lick account. We allowed no multiple compounding on any particular latency or interlick interval. Thus, an initial interlick interval of $400 \mathrm{msec}$ would have earned the same interest, $15 \%$ of 19 , as an initial interlick interval of $1,500 \mathrm{msec}$. Fractional licks were computed, but they were dropped at depletion time: Given 20.85 licks on account, the water shutter would close at the 20th lick. To avoid runaway accounts, we limited them to 60 . This precaution may have been unnecessary, for 60 -lick accounts proved infrequent.

We found that the rats deferred consumption at the $15 \%$ interest rate by deferring the next water lick, but the $25 \%$ rate had no effect on the interlick interval. Interest did not affect latency.

We based our conclusions on one-way repeatedmeasures analyses of variance and planned comparisons applied to the criterion sessions. Atop Figure 1 is the percentage of interlick intervals longer than the compounding period. The five points differed significantly $[F(4,20)$ $=6.00, p<.01]$. Because the three baseline measurements at $0 \%$ did not differ significantly from one another, they showed no order effect. When we pooled those three for planned comparison with the interest-bearing conditions, we found that the percentage of interlick intervals longer than the compounding period was significantly greater at $15 \%$ than either $0 \%$ or $25 \%[F(1,20)=18.16$ and 12.59, $p<.001$ and $p<.01$, respectively]. The $25 \%$ and $0 \%$ conditions did not differ significantly $(F<1)$. Precisely the same conclusions were supported by statistical analysis of the average interlick intervals at the bottom of Figure 1. Latencies displayed no significant interest-rate effect. For example, latency averaged about $770 \mathrm{msec}$ at the $0 \%$ baseline rate, $775 \mathrm{msec}$ at $15 \%$, and $720 \mathrm{msec}$ at $25 \%$, all statistically identical.

At $0 \%$, the rats averaged 24 water licks per accesssignificantly more than the scheduled number, 20 , because they made extra licks before the shutter could close completely (Buxton \& Allison, 1990). Still greater were the means recorded at $15 \%$ and $25 \%, 33.7$ and 33.9 water
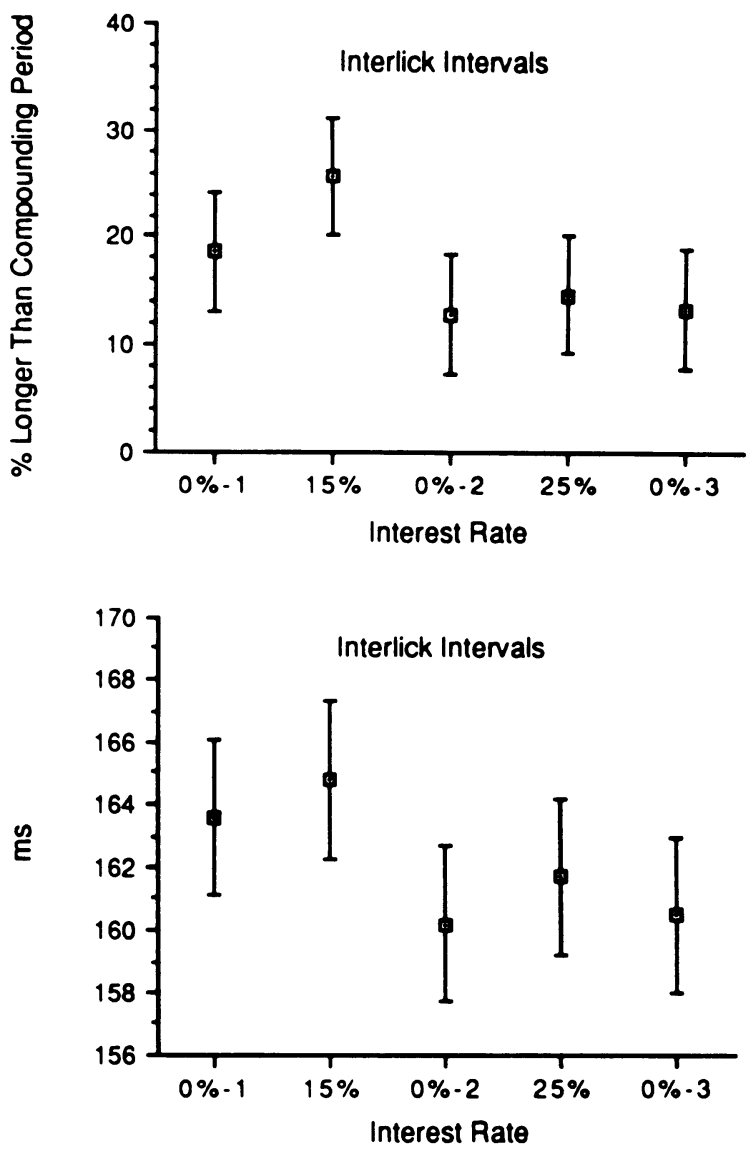

Figure 1. Percentage of interlick intervals longer than the compounding period (top), and median interlick interval (bottom). Each point is a group mean $(n=6)$; vertical lines show the root mean square error.

licks per access. These observations may identify the rat as a target saver. Browning and Browning (1983) used target saving to explain why a person might save less at higher interest rates. If the target is a $\$ 5,000$ sailboat, at $15 \%$ the sailor must save $\$ 4,348$ to hit the $\$ 5,000$ target, but only $\$ 4,000$ at $25 \%$. Given a higher interest rate, the target saver need not save so much. Our thirsty rats may have acted as savers with a target of 34 water licks per access-out of reach at $0 \%$, but reachable at $15 \%$ by means of a longer interlick interval. At the higher interest rate, $25 \%$, they could and did reach the same target without increasing the interlick interval. This target-saver concept implies that if the $0 \%$ schedule had allowed 34 licks per access, no positive interest rate would have induced the rat to defer consumption.

Conventional theory might interpret our results in terms of two opposite effects, substitution and income, brought into play when changing rates alter the relative cost of present and future consumption. Because present consumption grows more costly as interest rates rise, we tend to substitute future for present consumption and therefore defer. But rising interest rates bring in addition a rise in 
income. If consumption acts as a normal good, both present and future consumption will increase with income. Thus, the net effect on present consumption results in theory from opposite substitution and income effects. The substitution (income) effect of a rising interest rate discourages (encourages) present consumption.

Faced with the prospect of several water licks, our rats licked right away, but they deferred subsequent licks in response to a $15 \%$ interest rate for deferment. A still higher rate, $25 \%$, had no significant effect on latency or interlick interval. Thus, the thirsty rat may drink a little as soon as it can and only then respond to extrinsic rewards for deferment of consumption. In terms of conventional economic theory, the $15 \%$ rate created a substitution effect (less consumption now) that outweighed its income effect (more consumption now). As the rate increased, the income effect grew faster than the substitution effect, and the two effects canceled at $25 \%$.

Our results may have useful implications for experiments on self-control, where subjects often choose a small immediate reward over a large delayed reward (Logue, 1988). A large delayed reward might prove more popular if we could consume a little right away without sacrificing the chance for more of the same later on. Our rats licked the water spout about as soon as they could, but readily deferred licks that remained on account. A child might readily eat one pretzel now, and two later, in preference to two pretzels now. Impulsive behavior might occur more often under the conventional procedure, where the child must wait a long time for any of the three, and therefore chooses instead the two immediate pretzels.

\section{REFERENCES}

Boskin, M. J. (1978). Taxation, saving, and the rate of interest. Journal of Political Economy, 86, 3-27.

Browning, E. K., \& Browning, J. M. (1983). Microeconomic theory and applications. Boston: Little, Brown.

Buxton, A., \& Allison, J. (1990). Efficiency and persistence of licking in rats. Physiology \& Behavior, 47, 239-247.

HALL, R. E., \& TAYLOR, J. B. (1988). Macro-economics: Theory, performance, and policy (2nd ed.). New York: Norton.

KEYNES, J. M. (1936). The general theory of employment, interest, and money. London: Macmillan.

LOGUE, A. W. (1988). Research on self-control: An integrating framework. Behavioral \& Brain Sciences, 11, 665-707.

WEBER, W. E. (1970). The effect of interest rates on aggregate consumption. American Economic Review, 60, 591-600.

WRIGHT, C. (1969). Saving and the rate of interest. In A. C. Harberger \& M. J. Bailey (Eds.), The taxation of income from capital (pp. 275300). Washington: Brookings Institution.

(Manuscript received October 25, 1990.) 